Conclusion The expression of $\mathrm{I}_{\mathrm{Cl}}$, swell in atrial myocardium of rabbits with heart failure was significantly increased. $\mathrm{I}_{\mathrm{Cl}}$, swell may play a role in the vulnerability to atrial fibrillation in dilated atria with heart failure.

[gw22-e0411] CHANGES OF SWELLING-ACTIVATED CHLORIDE \section{CHANNELS IN ATRIAL MYOCARDIUM OF RABBITS WITH HEART FAILURE}

Cao Feng, Huang Cong-Xin, Jiang Hong, Wang Teng, Tang Yan-Hong, Wang Xi Department Of Cardiology, Renmin Hospital of Wuhan University, Wuhan, China

10.1136/heartjnl-2011-300867.101

Objective Heart failure is associated with an increased incidence of atrial fibrillation in patients with chronic heart failure. The potential mechanism has not been well explored. Recent study has demonstrated that swelling-activated chloride channel $\left(\mathrm{I}_{\mathrm{Cl} \text {, swell }}\right)$ may promote atrial fibrillation in dilated atria. The purpose of the present study was to observe the changes of SACs in isolated atrial myocardium after heart failure in rabbits.

Methods Twenty rabbits were randomly divided into two groups: control group ( $\mathrm{n}=10$, sham-operation rabbits 5$)$ and heart failure $(n=10)$ group. Chronic heart failure model was produced by combined aortic regurgitation and coarctation of the abdominal aorta which was practiced two weeks later. Ten weeks after operation, changes of heart structure and function were inspected by cardiac colour Doppler ultrasound. The pathological change was analysed by histological haematoxylin-eosin staining. The expression of $\mathrm{I}_{\mathrm{Cl}}$, swell $\mathrm{mRNA}$ and proteins were detected by RT-PCR and Western blotting, respectively.

Results The left artia inner diameter of heart failure group was significantly enlarged $(p<0.05)$ compared with the control group. The pathological examination of heart failure group was consistent with the histological changes of heart failure. The expression of $\mathrm{I}_{\mathrm{Cl} \text {, swell }}$ protein and $\mathrm{mRNA}$ in heart failure group were markedly increased $(p<0.01)$. 